\title{
First Record of the Mourning Gecko, Lepidodactylus lugubris (Duméril \& Bibron 1836), on Grand Cayman, Cayman Islands
}

Matthias Goetz ${ }^{1}$ and Frederic J. Burton ${ }^{2}$

\begin{abstract}
${ }^{1}$ Durrell Wildlife Conservation Trust, Les Augrès Manor, Trinity, Jersey JE3 5BP, British Channel Islands (Matt.Goetz@durrell.org) ${ }^{2}$ Cayman Islands Government, Department of Environment, Box 10202, Grand Cayman KY1-1002, Cayman Islands, British West Indies
\end{abstract}

\begin{abstract}
7 he Cayman Islands harbor a number of introduced alien
1 species, including several invasive reptilian species (e.g., Iguana iguana, Anolis sagrei, Trachemys scripta, Pantherophis guttatus and Indotyphlops braminus; Edgar et al. 2009; Dawson et al. 2015). Hemidactylus mabouia is the only invasive gekkotan species on record. It is established on all three Cayman Islands, whereas Gonatodes albogularis has been recorded on
\end{abstract}

Grand Cayman but probably is not established (Edgar et al. 2009). Here we present the discovery of a third non-native gecko, which has the potential to become established in the Cayman Islands.

The Mourning Gecko Lepidodactylus lugubris (Duméril and Bibron 1836) is a small, parthenogenetic, mostly nocturnal gecko widely distributed throughout much of the

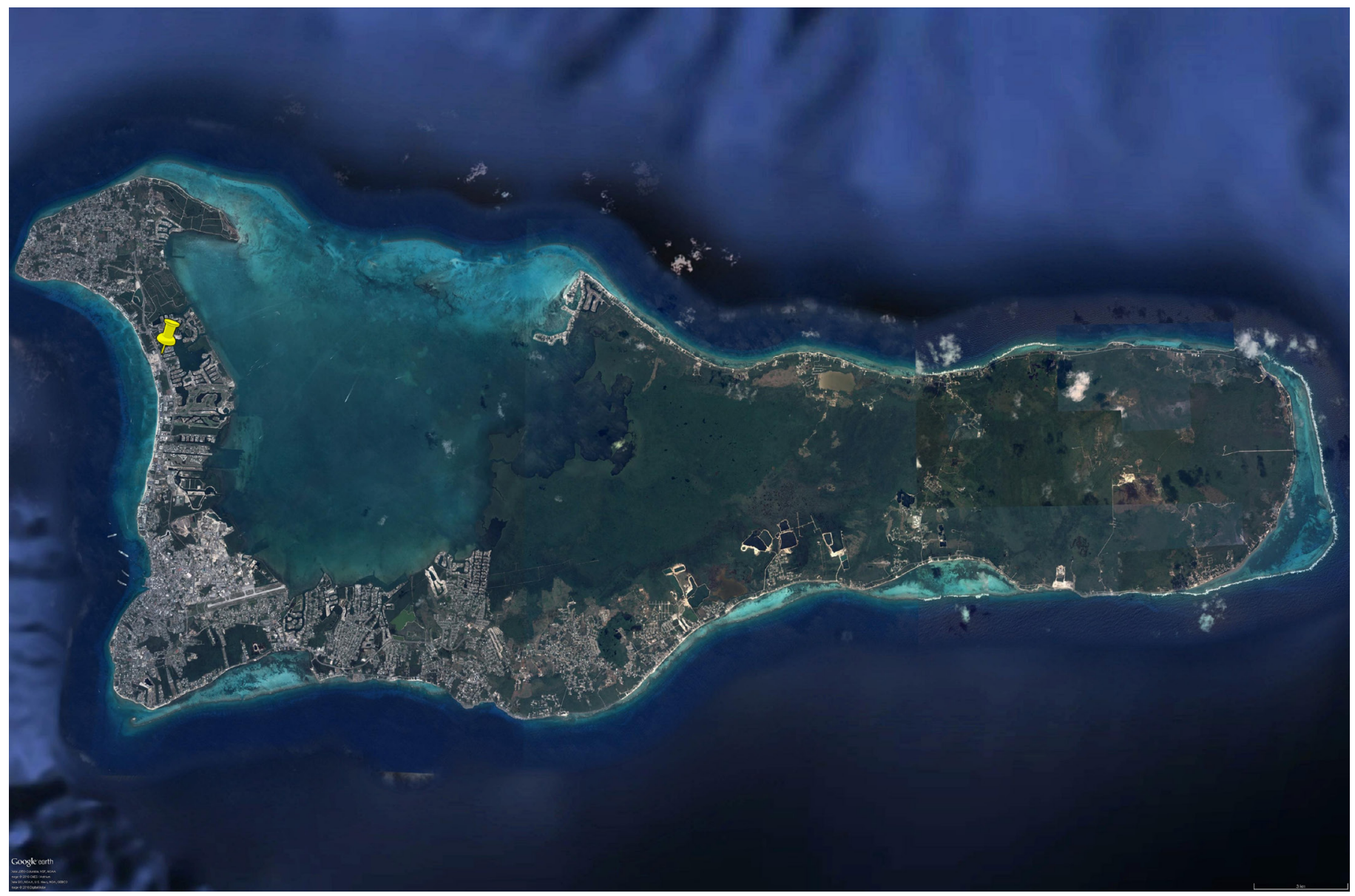

Fig. 1. Google Earth ${ }^{\odot}$ map showing the location on Grand Cayman, Cayman Islands, where a Mourning Gecko (Lepidodactylus lugubris) was captured. Map data: Google Earth, LDEO-Columbia, NSF, NOAA, SIO, U.S. Navy, NGA, GEBCO. Photograph (C) CNES/Airbus. 
Indo-Pacific region (Bauer and Henle 1994). In the Western Hemisphere, it has been introduced into the mainland countries of Brazil, Nicaragua, Costa Rica, Panama, Venezuela, Colombia, Ecuador, Suriname, and the USA (Florida), as well as to more remote locations including the Galapagos Islands, Hawaii, and Easter Island (Hoogmoed and Avila 2015). The only Caribbean islands from which this species has been recorded to date are Guadeloupe (Lorvelec et al. 2011), The Bahamas (Krysko and MacKenzie-Krysko 2016), and Cuba (Bosch and Paez 2017).

Late in the morning of 8 September 2016, the first author observed a subadult Lepidodactylus lugubris on the patio doorframe of a residential house in the Cypress Pointe area of Grand Cayman (19²1'08.30”N, 81 22 '52.00”W; Fig. 1). It was photographed (Fig. 2), measured (SVL $34 \mathrm{~mm}$ ), humanely euthanized, and is now preserved in ethanol at the Cayman Islands Government, Department of Environment as a voucher specimen. The identity of the specimen was confirmed from the photograph by Dr. Arthur C. Echternacht (University of Tennessee, Knoxville).

Grand Cayman is a major tourist and business destination. People arrive by plane and cruise ships and goods are imported from various destinations, providing many opportunities for alien species to arrive undetected. This specimen was found in a residential area, about $6 \mathrm{~km}$ from both the

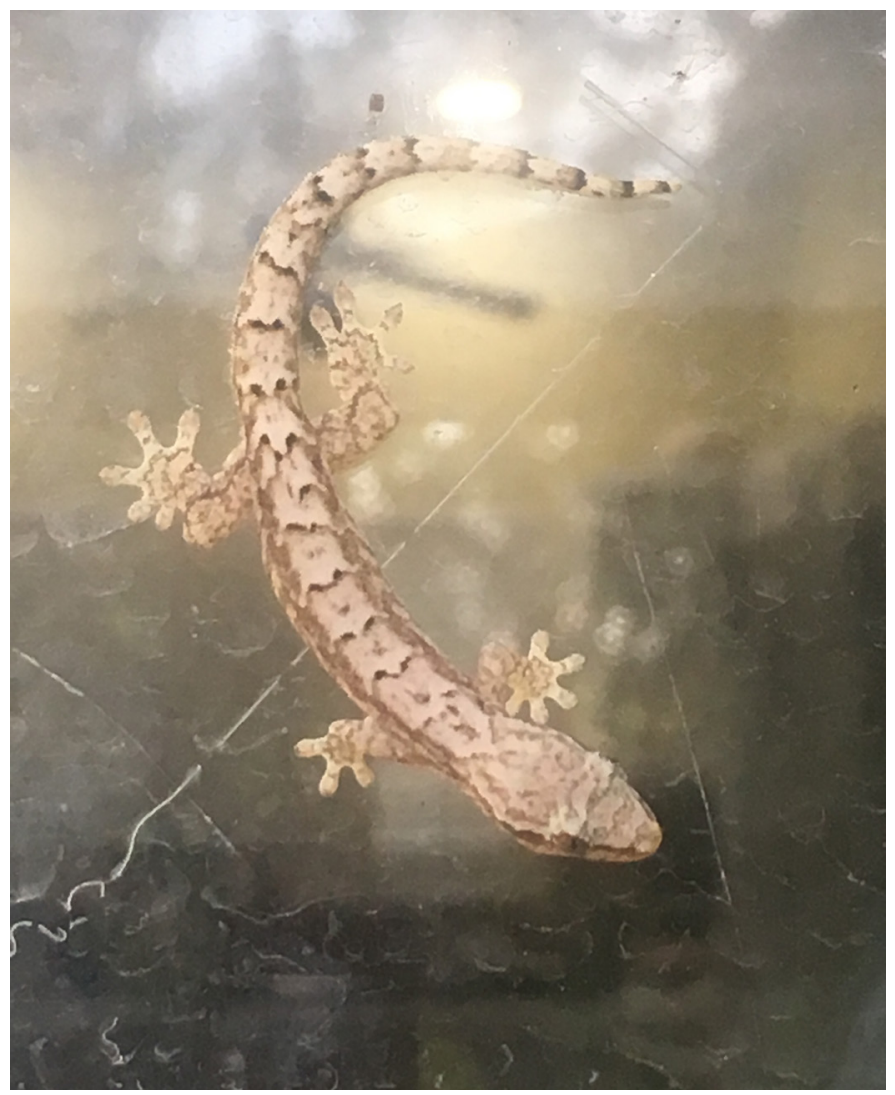

Fig. 2. The subadult Mourning Gecko (Lepidodactylus lugubris) discovered on Grand Cayman. Photograph by F.J. Burton. harbor and the airport. Either of these could be an entry route, the gecko likely being a stowaway in luggage (e.g., on a passenger flight from Florida or The Bahamas). However, a major building site for a new hotel complex is a mere 100 $\mathrm{m}$ away across a four-lane road, suggestive of another possible entry route, via building supplies shipped in from Florida or some other locality. Although we did not identify the clonal identity of the specimen, more research along those lines could shed additional light onto the distribution patterns of this recent colonizer in the Caribbean region (Ineich 1999).

As a unisexual, parthenogenetic form, Lepidodactyus lugubris could rapidly colonize Grand Cayman. However, the omnipresent and well-established Hemidactylus mabouia, a larger and more aggressive bisexual invasive competitor, might prevent range expansion (Bolger and Case 1992; Petren et al. 1993; Brown et al. 2002). Focused surveys would be required to determine whether the specimen found in 2016 was indeed the initial introduction of this species. Ongoing long-term sampling efforts across the island will be necessary to evaluate its success in colonizing this particular island ecosystem.

\section{Acknowledgements}

We thank Giles Shaxted, Grand Cayman, BWI, for his hospitality at the accommodation where the gecko was found.

\section{Literature Cited}

Bauer, A.M. and K. Henle. 1994. Das Tierreich 109 (Part). Familia Gekkonidae. Part I. Australia and Oceania. Walter de Gruyter, Berlin.

Bolger, D.T. and T.J. Case. 1992. Intra-specific and inter-specific interference behavior among sexual and asexual geckos. Animal Behavior 44: 21-30.

Brown, S.G., R. Lebrun, J. Yamasaki, and D. Ishii-Thoene. 2002. Indirect competition between a resident unisexual and an invading gecko. Behaviour 139: 1161-1173.

Bosch, R.A. and R.B. Páez. 2017. First record from Cuba of the introduced Mourning Gecko, Lepidodactylus lugubris (Duméril and Bibron, 1836). BioInvasions Records 6: 297-300.

Dawson, J., S. Oppel, R.J. Cuthbert, N. Holmes, J.P. Bird, S.H.M. Butchard, D.R. Spatz, and B. Tershy. 2015. Prioritizing islands for the eradication of invasive vertebrates in the United Kingdom overseas territories. Conservation Biology 29: 143-153.

Edgar, P. 2009. The Amphibians and Reptiles of the UK Overseas Territories, Crown Dependencies and Sovereign Base Areas - Species Inventory and Overview of Conservation and Research Priorities. Version 1. The Herpetological Conservation Trust, Dorset, United Kingdom.

Hoogmoed, M.S. and T.C.S. Avila-Pires. 2015. Lepidodactylus lugubris (Duméril \& Bibron 1836) (Reptilia: Gekkonidae), an introduced lizard new for Brazil, with remarks on and correction of its distribution in the New World. Zootaxa 4000: $90-110$.

Ineich, I. 1999. Spatio-temporal analysis of the unisexual-bisexual Lepidodactylus lugubris complex (Reptilia, Gekkonidae), pp. 199-228. In: H. Ota (ed.). Tropical Island Herpetofauna: Origin, Current Diversity, and Conservation. Elsevier, Amsterdam, The Netherlands.

Krysko, K.L. and C. MacKenzie-Krysko. 2016. First report of the Mourning Gecko, Lepidodactylus lugubris (Duméril \& Bibron 1836), from The Bahamas. Caribbean Herpetology 54: 1-2.

Lorvelec, O., A. Levesque, and A.M. Bauer. 2011. First record of the Mourning Gecko (Lepidodactylus lugubris) on Guadeloupe, French West Indies. Herpetology Notes 4: 291-294.

Petren, K., D.T. Bolger, and T.J. Case. 1993. Mechanisms in the competitive success of an invading sexual gecko over an asexual native. Science 259: 354-358. 